\title{
Sociodemographic characteristics determine dietary pattern adherence during pregnancy
}

\author{
Maria Beatriz Trindade de Castro ${ }^{1, *}$, Ana Amélia Freitas Vilela ${ }^{1,2}$, \\ Alessandra Silva Dias de Oliveira ${ }^{2}$, Maria Cabral ${ }^{3}$, Rita Adriana Gomes de Souza ${ }^{4}$, \\ Gilberto Kac ${ }^{1}$ and Rosely Sichieri ${ }^{5}$ \\ ${ }^{1}$ Nutritional Epidemiology Observatory, Department of Social and Applied Nutrition, Institute of Nutrition Josué de \\ Castro, Federal University of Rio de Janeiro, Avenida Carlos Chagas Filho 367, CCS - Bloco J - $2^{\circ}$ andar - sala 29, \\ Cidade Universitária - Ilha do Fundão, Rio de Janeiro, RJ, 21941-590, Brazil: ${ }^{2}$ Graduate Program in Nutrition, \\ Institute of Nutrition Josué de Castro, Federal University of Rio de Janeiro, Rio de Janeiro, RJ, Brazil: ${ }^{3}$ EPIUnit - \\ Institute of Public Health, University of Porto, Porto, Portugal: ${ }^{4}$ Department of Public Health, Institute of Public Health, \\ Federal University of Mato Grosso, Cuiabá, MT, Brazil: ${ }^{5}$ Department of Epidemiology, Institute of Social Medicine, \\ State University of Rio de Janeiro, Rio de Janeiro, R, Brazil
}

Submitted 17 April 2015: Final revision received 12 August 2015: Accepted 18 August 2015: First published online 24 September 2015

\begin{abstract}
Objective: Sociodemographic factors may affect adherence to specific dietary patterns during pregnancy. The present study aimed to identify dietary patterns during pregnancy and associated factors among Brazilian pregnant women.

Design: A cross-sectional analysis. Dietary intake was evaluated with a semiquantitative FFQ during the first postpartum week; the time frame included the second and third gestational trimesters. Principal component analysis was used to identify dietary patterns during pregnancy. Sociodemographic data were obtained using a structured questionnaire. Multiple linear regressions were applied to test the associations between the sociodemographic factors and dietary patterns.

Setting: Mesquita, Rio de Janeiro, Brazil, 2011.

Subjects: Postpartum women ( $n$ 327) who were $18-45$ years of age and Mesquita residents.

Results: Three different dietary patterns were identified: 'healthy' (mainly comprising legumes, vegetables and fruits), 'mixed' (mainly comprising candy, butter and margarine, and snacks) and 'traditional' (mainly comprising beans and rice). Women with a higher monthly per capita family income $(\beta=0 \cdot 0006 ; 95 \% \mathrm{CI}$ $0.0001,0.001 ; P=0.011)$ and women of older age $(\beta=0.021 ; 95 \% \mathrm{CI}-0.001$, $0.042 ; P=0.058)$ were more likely to adhere to the 'healthy' dietary pattern. Women with higher parity were less likely to adhere to the 'healthy' pattern $(\beta=-0.097 ; 95 \% \mathrm{CI}-0 \cdot 184,-0 \cdot 009 ; P=0.030)$ and were more likely to adhere to the 'traditional' pattern $(\beta=0.098 ; 95 \%$ CI $0.021,0 \cdot 175 ; P=0 \cdot 012)$. Although not statistically significant, older women were less likely to adhere to the 'mixed' $(\beta=-0.017 ; 95 \% \mathrm{CI}-0.037,0.003 ; P=0.075)$ and 'traditional' $(\beta=-0.018 ; 95 \% \mathrm{CI}$ $-0.037,0 \cdot 001 ; P=0.061)$ dietary patterns.

Conclusions: Monthly per capita family income, parity and maternal age were factors associated with adherence to a healthy diet during pregnancy.
\end{abstract}

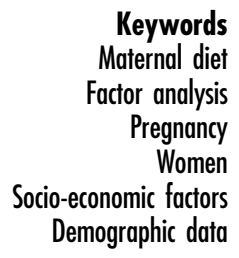

Adequate dietary intake during pregnancy plays an important role in women's health, in perinatal outcomes, and in fetal growth and development ${ }^{(1,2)}$. The quality of a woman's diet during pregnancy ${ }^{(2-4)}$ and excessive ${ }^{(5)}$ or restricted intake ${ }^{(6)}$ are known risk factors and may impact maternal health in addition to childhood and adolescent health $^{(7)}$. Dietary restrictions are associated with nutritional deficiencies and low birth weight ${ }^{(4,6)}$, whereas excessive gestational weight gain seems to be associated with fetal macrosomia ${ }^{(5,8)}$. These conditions are considered risk factors for the development of obesity and chronic diseases later in adult life.

Dietary intake during pregnancy is traditionally assessed by examining the energy and macronutrient intakes or the intakes of certain food groups or micronutrients ${ }^{(1-3)}$, which may then be associated with inadequate nutritional 
status and imbalanced maternal diet. Since the early 1990s, principal component analysis has been used to identify dietary patterns during pregnancy ${ }^{(9-11)}$. This method allows for diet to be described as a whole, and it can be used to assess the role of social and economic factors in the likelihood of adherence to a certain dietary pattern. Thus, principal component analysis seems to be a relatively good and comprehensive method for exploring food intake during pregnancy. The use of dietary patterns may also help capture some of the complexities of diet, which are often lost in nutrient-based analyses. Similarly, principal component analysis provides additional information for exploring the relationship between nutrition and health ${ }^{(12-14)}$.

There are still gaps regarding the impact of various socio-economic and demographic factors on adequate dietary intake during pregnancy ${ }^{(9,15)}$. In Brazil, a study of 421 pregnant women, conducted by Castro et al. ${ }^{(9)}$, indicated that schooling and family income were positively associated with a 'healthy' dietary pattern. In a multi-ethnic population study of pregnant women conducted in Norway it was observed that non-European women were more likely to adhere to an unhealthy dietary pattern compared with European women ${ }^{(15)}$. Additionally, a positive association between education and a 'healthconscious' diet was verified in a British population-based study with 12053 pregnant women ${ }^{(11)}$. Also, age, regional habits, lower parity and marital status have been suggested to be associated with dietary quality ${ }^{(10,16,17)}$.

The identification of whether certain sociodemographic factors are associated with adherence to specific dietary patterns may help shape the actions of health professionals according to the social and economic profile of their patient population. Particularly, in a developing country such as Brazil, it was shown that low income may affect food and dietary patterns ${ }^{(9,16,17)}$. These relationships emphasise the recent evidence that suggests these possible associations should be further explored. Therefore, the aim of the present study was to identify gestational dietary patterns and verify whether they are associated with sociodemographic factors in low-income Brazilian women who are pregnant.

\section{Materials and methods}

\section{Design and study population}

A cross-sectional study was conducted of women who gave birth between February 2009 and February 2011 in the maternity ward of the Municipal Hospital Leonel de Moura Brizola, located in Mesquita, Rio de Janeiro, Brazil.

The maternity ward sees women with low-risk term pregnancies. Women aged $18-45$ years, without twin pregnancy or pre-existing chronic diseases (diabetes mellitus, cancer and renal disease) were eligible to participate in the study. Of the 338 women who were invited to participate in the study, four $(1.2 \%)$ refused to answer the questionnaire and seven $(2 \cdot 1 \%)$ were excluded from the analysis because their energy intake exceeded $25104 \mathrm{~kJ}$ $(6000 \mathrm{kcal})^{(18)}$. A dietary intake of less than $2510 \mathrm{~kJ}$ ( $600 \mathrm{kcal})$ was an exclusion criterion, but none of the participants were excluded based on this criterion. Thus, the study included data on 327 (96.7\%) participants.

Sociodemographic data were collected during the immediate postpartum period (first week after birth) through a structured questionnaire and included the following variables: schooling (years of schooling), parity (number of parturitions), marital status (married/stable partnership or single/other), age (years), self-reported skin colour (white or black/brown) and monthly per capita family income (\$US). The sociodemographic variables were used as predictor variables of the dietary patterns.

Early pregnancy weight was measured until 13 weeks of gestation and was obtained from the women's prenatal cards. When the early pregnancy weight was not recorded on the prenatal cards, it was self-reported by the women. Height was measured while the women were barefoot by using a portable stadiometer that was calibrated to $0.1 \mathrm{~cm}$ (Alturexata, Belo Horizonte, Brazil). The anthropometric measures were assessed following the protocol established by Lohman et $a l .{ }^{(19)}$.

\section{Dietary patterns}

All of the women answered a validated semi-quantitative $\mathrm{FFQ}^{(20)}$; the time frame included the last six months of pregnancy to avoid distortions in consumption by nausea and dislike of the early stages of pregnancy. The FFQ options were converted into grams of daily intake. The daily intakes of nutrients and energy were estimated using a program developed by Sichieri ${ }^{(21)}$ in the statistical software package SAS version 9.1, and were obtained by multiplying the previous portion of each food ${ }^{(22)}$ by its respective daily frequency. The Brazilian Food Composition Table ${ }^{(23)}$ was used as the nutritional composition database for the conversion of foods into nutrients and energy. The US Department of Agriculture Food Composition Table ${ }^{(24)}$ was used in the absence of certain food items from the Brazilian table.

The eighty-one items on the FFQ considering nutritional composition were grouped into twenty-eight food groups, including the following foods and beverages: (i) green leafy vegetables (lettuce, kale and cabbage); (ii) legumes and other vegetables (okra, chayote, cucumber, onion, pumpkin, zucchini, carrot, pea pod, beet, cauliflower, red/ green/yellow pepper and tomato); (iii) fruits (orange, banana, papaya, apple, melon, pineapple, mango and grape); (iv) rice; (v) beans; (vi) wheat; (vii) breads; (viii) potatoes and cassava; (ix) pasta and Italian foods; (x) milk; (xi) dairy products (yoghurt, cheese and cream cheese); (xii) eggs; (xiii) fish; (xiv) sardines; (xv) chicken; (xvi) red meat; (xvii) fatty and processed meats (steak, oxtail, pork, sausages and giblets); (xviii) sugar; (xix) cakes and cookies/crackers; (xx) butter and margarine; (xxi) other 
fats (bacon and mayonnaise); (xxii) snacks (pizza, savoury snacks, French fries, popcorn and patties); (xxiii) soda; (xxiv) candy; (xxv) herbal mate and tea; (xxvi) fruit juice; (xxvii) beer and wine; and (xxviii) coffee. Some of the individual food and beverage items were kept separately due to their higher frequency of intake among the pregnant women and their cultural relevance (e.g. rice and beans). Complex dishes such as lasagne, pasta and gnocchi were included in the pasta and Italian foods group. The questionnaire included a specific Brazilian mixed dish called churrasco (steak) that comprises more than one type of meat; it was included in the fatty and processed meats group.

Dietary patterns were identified using factor analysis for principal component analysis. A Kaiser-Meyer-Olkin statistic $>0 \cdot 60$ was applied to test for method adequacy. The following criteria were used to identify the number of patterns (factors): (i) eigenvalues $>1.50$ and (ii) the inflection point of the eigenvalues from the Cattell scree test (screeplot) ${ }^{(12,13,25)}$. After orthogonal rotation of the varimax matrix, we used a factor loading cut-off of $0 \cdot 20$ to limit the inter-correlation between the dietary variables that were obtained. Cronbach's $\alpha$ was used to measure the internal consistency of a set of items that was identified as a group. Subsequently, the factors were named according to the dietary composition of the predominant food groups.

\section{Data analysis}

After extraction of the factors, unvariate linear regression was performed to evaluate the association between the sociodemographic variables and the identified dietary patterns. The sociodemographic variables that had $P<0 \cdot 20$ in the univariate regression were included in the multivariate linear regression model. Energy intake (kcal) and pre-pregnancy BMI (early pregnancy weight $(\mathrm{kg}) /$ height $^{2}$ $\left(\mathrm{m}^{2}\right)$ ) were used as adjustment variables. Aside from skin colour, all of the other predictor variables (schooling, monthly per capita family income, parity, age and marital status) were associated with at least one of the factors retained $(P<0.05)$ in the univariate linear regression model. All estimates were calculated using SAS version 9·1.

\section{Ethical aspects}

The study and the informed consent form were approved by the Research Ethics Committee of the Institute of Social Medicine at the State University of Rio de Janeiro (protocol number CAAE 0022.0.259.000-09). The proposed project was in accordance with the ethical principles recommended by the Brazilian National Health Council.

\section{Results}

The mean baseline characteristics of the 327 postpartum women were as follows: 24.8 (SD 5.5) years of age; $2 \cdot 2$ (SD 1.4 ) parturitions; monthly per capita family income of
Table 1 Baseline characteristics of the 327 postpartum women. Rio de Janeiro, Brazil, 2011

\begin{tabular}{|c|c|c|}
\hline Variable & Mean & SD \\
\hline \multicolumn{3}{|l|}{ Anthropometric } \\
\hline Early pregnancy weight (kg) & 69.5 & 13.7 \\
\hline Height (m) & 1.61 & 0.064 \\
\hline Pre-pregnancy BMI $\left(\mathrm{kg} / \mathrm{m}^{2}\right)$ & 23.6 & 4.6 \\
\hline \multicolumn{3}{|l|}{ Dietary intake } \\
\hline Energy (kJ) & 12108 & 4523 \\
\hline Energy (kcal) & 2894 & 1081 \\
\hline \multicolumn{3}{|l|}{ Sociodemographic } \\
\hline Age (years) & 24.8 & 5.5 \\
\hline Schooling (years) & 3.9 & $2 \cdot 3$ \\
\hline Parity $(n)$ & $2 \cdot 2$ & 1.4 \\
\hline \multirow[t]{2}{*}{ Family income (\$US)* } & 338 & 211 \\
\hline & $n$ & $\%$ \\
\hline \multicolumn{3}{|l|}{ Sociodemographic } \\
\hline \multicolumn{3}{|l|}{ Skin colour (self-reported) } \\
\hline Black or brown & 273 & 83.5 \\
\hline White & 54 & $16 \cdot 5$ \\
\hline \multicolumn{3}{|l|}{ Civil status } \\
\hline Married/union or stable partnership & 239 & $73 \cdot 3$ \\
\hline Single/other & 87 & $26 \cdot 7$ \\
\hline
\end{tabular}

*Monthly per capita family income.

\$US 338 (SD 211); pre-pregnancy BMI of $23 \cdot 6$ (sD 4.6) kg/m²; and total daily energy intake of 12108 (sD 4523) kJ (2894 (SD 1081) kcal). More than $80 \%$ of the pregnant women reported that their skin colour was black or brown, and $73.3 \%$ of the women were classified as married or having a stable partner (Table 1).

Three dietary patterns were identified: 'healthy', 'mixed' and 'traditional'. The Kaiser-Meyer-Olkin statistic was 0.65 , and the eigenvalues were 3.37, 2.05 and 1.67, respectively. The cumulative variance was $25.3 \%$. The 'healthy' pattern explained $12 \cdot 0 \%$ of the total variance and comprised green leafy vegetables, legumes and other vegetables, milk, dairy products, fruits, red meat, chicken, herbal mate and tea, and fruit juice. The second pattern was the 'mixed' pattern; it explained $7 \cdot 3 \%$ of the variance and comprised eggs, pasta and Italian foods, other fats, cakes and cookies/crackers, butter and margarine, fatty and processed meats, snacks, soda, sardines and candy. The third pattern was the 'traditional' pattern; it explained $6.0 \%$ of the variance and comprised rice, beans, wheat, potatoes and cassava, breads, sugar and coffee. The standardised Cronbach's $\alpha$ coefficient was 0.65, 0.59 and 0.55 , respectively, for the 'healthy', 'mixed' and 'traditional' patterns. Prior communality was estimated, and the low and high communality was 0.44 for beer and wine and 0.82 for fruits, respectively (Table 2 ).

The older women $(\beta=0.021 ; 95 \%$ CI $-0.001,0.042$; $P=0.058)$ and the women with a higher monthly per capita family income $(\beta=0 \cdot 0006 ; 95 \%$ CI $0 \cdot 0001,0 \cdot 001$; $P=0.011$ ) tended to adhere more to the 'healthy' dietary pattern, whereas the women with lower parity ( $\beta=-0.097 ; 95 \%$ CI $0 \cdot 184,-0.009 ; P=0.030)$ tended to adhere less to the 'healthy' dietary pattern. The women 
Table 2 Factor loadings of rotated factor matrix and initial communalities for major pregnancy dietary patterns for 327 women at postpartum. Rio de Janeiro, Brazil, 2011

\begin{tabular}{|c|c|c|c|c|}
\hline \multirow[b]{2}{*}{ Food/food group } & \multicolumn{3}{|c|}{ Dietary pattern* } & \multirow[b]{2}{*}{$h^{2}$} \\
\hline & 'Healthy' & 'Mixed' & 'Traditional' & \\
\hline Green leafy vegetables & 0.488 & 0.027 & -0.030 & 0.62 \\
\hline Legumes and other vegetables & 0.658 & -0.048 & -0.003 & 0.62 \\
\hline Milk & 0.395 & 0.090 & 0.039 & 0.66 \\
\hline Dairy products & 0.421 & 0.158 & 0.008 & 0.73 \\
\hline Fruits & 0.533 & 0.116 & 0.152 & 0.82 \\
\hline Red meat & 0.309 & -0.036 & 0.205 & 0.74 \\
\hline Chicken & 0.320 & -0.135 & 0.110 & 0.58 \\
\hline Herbal mate and tea & 0.200 & 0.089 & 0.040 & 0.61 \\
\hline Fruit juice & 0.348 & -0.002 & -0.003 & 0.64 \\
\hline Fish & 0.173 & 0.133 & -0.012 & 0.54 \\
\hline Eggs & -0.004 & 0.245 & 0.197 & 0.56 \\
\hline Pasta and Italian foods & 0.133 & 0.242 & 0.064 & 0.66 \\
\hline Other fats & 0.049 & 0.357 & 0.246 & 0.75 \\
\hline Cakes and cookies/crackers & $0 \cdot 192$ & 0.309 & 0.193 & 0.80 \\
\hline Butter and margarine & $0 \cdot 140$ & 0.381 & -0.144 & 0.56 \\
\hline Fatty and processed meats & 0.012 & 0.242 & $0 \cdot 159$ & 0.57 \\
\hline Snacks & -0.043 & 0.374 & 0.214 & 0.71 \\
\hline Soda & 0.062 & 0.314 & 0.252 & 0.65 \\
\hline Sardines & -0.004 & 0.332 & -0.080 & 0.52 \\
\hline Candy & 0.261 & 0.491 & 0.028 & 0.71 \\
\hline Beer and wine & -0.055 & 0.193 & -0.038 & 0.44 \\
\hline Rice & -0.029 & 0.016 & 0.427 & 0.56 \\
\hline Beans & 0.049 & -0.048 & 0.482 & 0.60 \\
\hline Sweets & 0.093 & 0.160 & 0.288 & 0.76 \\
\hline Potato and cassava & 0.221 & 0.271 & 0.384 & 0.73 \\
\hline Breads & 0.137 & 0.060 & 0.381 & 0.72 \\
\hline Sugar & 0.040 & 0.216 & 0.305 & 0.67 \\
\hline Coffee & -0.015 & -0.057 & 0.287 & 0.50 \\
\hline Number of groups & 9 & 10 & 7 & \\
\hline Eigenvalue & 3.37 & 2.05 & 1.67 & \\
\hline$\%$ of variance explained & $12 \cdot 02$ & $7 \cdot 31$ & 5.96 & \\
\hline$\%$ of cumulative variance explained & $12 \cdot 02$ & $19 \cdot 33$ & $25 \cdot 30$ & \\
\hline
\end{tabular}

${ }^{*}$ Factor loadings $\geq 0.20$ were included in each dietary pattern.

with more parturitions $(\beta=0 \cdot 098 ; 95 \%$ CI $0 \cdot 021,0 \cdot 175$; $P=0 \cdot 012$ ) were more likely to adhere to the 'traditional' dietary pattern. Although the association was not statistically significant, maternal age was negatively associated with the 'mixed' $(\beta=-0.017 ; 95 \%$ CI $-0.037,0.003$; $P=0.075)$ and the 'traditional' $(\beta=-0.018 ; 95 \% \mathrm{CI}-0.037$, $0 \cdot 001 ; P=0 \cdot 061$ ) dietary patterns (Table 3 ).

\section{Discussion}

In the present study, three dietary patterns were identified among low-income Brazilian pregnant women, and they were labelled as 'healthy', 'mixed' and 'traditional'. The women with a higher monthly per capita family income were more likely to adhere to the 'healthy' pattern, whereas the women with higher parity were less likely to adhere to the 'healthy' pattern. In contrast, the women with higher parity were more likely to adhere to the 'traditional' pattern, whereas the older women showed a borderline negative association with this pattern. With the exception of a borderline association with maternal age, the sociodemographic factors examined were not associated with the 'mixed' dietary pattern.
Some studies suggest that sociodemographic factors influence adherence to dietary patterns ${ }^{(9)}$ and are related to differential access according to economic status and ethnicity $^{(15)}$. In our study, a positive association was observed between family income and the 'healthy' pattern. This finding is in agreement with other national studies that verified that women with the lowest education and income have been associated with the intake of traditional Brazilian food items ${ }^{(16)}$ and with a low consumption of healthy foods ${ }^{(17)}$. Brazil is a developing country and the frequency of low-income families is still quite common. In this regard, the present finding is particularly important and adds new evidence to the current literature as it shows that income is strongly associated with dietary choices. In a study among British pregnant women, the 'health-conscious' pattern (comprising salad, fruit, rice, pasta, oat- and bran-based breakfast cereals, fish, pulses, fruit juices and non-white bread) showed a negative association with financial difficulties and increasing parity $^{(11)}$; this is similar to our findings.

Our study found an inverse association between parity and the 'healthy' pattern. According to Goñi et al. ${ }^{(26)}$, a diet comprising fruits, dairy products and nuts during pregnancy was more common among nulliparous than 
Table 3 Unadjusted and adjusted ${ }^{\star}$ regression coefficients for the 'healthy', 'mixed' and 'traditional' dietary patterns according to sociodemographic variables for 327 women at postpartum. Rio de Janeiro, Brazil, 2011

\begin{tabular}{|c|c|c|c|c|c|c|c|c|c|}
\hline \multirow[b]{3}{*}{ Variable } & \multicolumn{9}{|c|}{ Dietary pattern } \\
\hline & \multicolumn{3}{|c|}{ 'Healthy' } & \multicolumn{3}{|c|}{ 'Mixed' } & \multicolumn{3}{|c|}{ 'Traditional' } \\
\hline & $\beta$ & $P$ & $95 \% \mathrm{Cl}$ & $\beta$ & $P$ & $95 \% \mathrm{Cl}$ & $\beta$ & $P$ & $95 \% \mathrm{Cl}$ \\
\hline \multicolumn{10}{|l|}{ Unadjusted } \\
\hline Age (years) & 0.010 & 0.343 & $-0.010,0.029$ & -0.023 & 0.022 & $-0.042,0.003$ & -0.007 & 0.456 & $-0.027,0.012$ \\
\hline Schooling (years) & 0.018 & 0.471 & $-0.031,0.067$ & 0.035 & $0 \cdot 169$ & $-0.014,0.084$ & 0.033 & 0.180 & $-0.015,0.080$ \\
\hline Family income (\$US)† & 0.0003 & 0.007 & $0.0001,0.0005$ & 0.0001 & 0.259 & $-0.0001,0.0003$ & -0.0003 & 0.025 & $-0.0005,0.0003$ \\
\hline Parity $(n)$ & -0.083 & 0.041 & $-0.163,-0.003$ & -0.015 & 0.715 & $-0.095,0.065$ & 0.142 & $<0.001$ & $0.065,0.219$ \\
\hline Marital status & 0.023 & 0.688 & $-0.090,0.136$ & 0.002 & 0.977 & $-0.111,0.115$ & 0.125 & 0.026 & $0.015,0.236$ \\
\hline Skin colour & 0.015 & 0.761 & $-0.084,0.114$ & -0.026 & 0.600 & $-0.125,0.072$ & 0.021 & 0.678 & $-0.077,0.118$ \\
\hline \multicolumn{10}{|l|}{ Adjusted } \\
\hline Age (years) & 0.021 & 0.058 & $-0.001,0.042$ & -0.017 & 0.075 & $-0.037,0.003$ & -0.018 & 0.061 & $-0.037,0.001$ \\
\hline Schooling (years) & 0.019 & 0.406 & $-0.026,0.065$ & 0.025 & $0 \cdot 132$ & $-0.018,0.067$ & 0.010 & 0.628 & $-0.030,0.050$ \\
\hline Family income (\$US)† & 0.0006 & 0.011 & $0.0001,0.001$ & 0.0004 & 0.090 & $-0.0001,0.001$ & -0.0004 & 0.102 & $-0.001,0.0001$ \\
\hline Parity $(n)$ & -0.097 & 0.030 & $-0.184,-0.009$ & 0.007 & 0.861 & $-0.074,0.089$ & 0.098 & 0.012 & $0.021,0.175$ \\
\hline Marital status $\ddagger$ & 0.030 & 0.588 & $-0.078,0.137$ & 0.0004 & 0.993 & $-0.100,0.101$ & 0.073 & 0.131 & $-0.022,0.168$ \\
\hline
\end{tabular}

${ }^{*}$ The models were adjusted for total energy intake and pre-gestational BMI

†Monthly per capita family income.

¥Married/union or stable partnership or single/other.

multiparous women. This finding was based on a crosssectional survey of 5087 pregnant women in Spain. Additionally, the authors found a higher intake of sausages, bread and meat among the multiparous pregnant women. Ferrer et al. ${ }^{(27)}$ showed that parity was positively associated with the 'caloric' pattern characterised by a high intake of energy-dense foods and with the low intake of fruits and vegetables. Other studies are in accordance with our results ${ }^{(11,28)}$, where it was observed that increasing parity is associated with high adherence to unhealthy dietary patterns during pregnancy. This finding raises the hypothesis that health consciousness may occur more frequently among nulliparous women. In general, higher-income and older individuals tend to choose healthier foods ${ }^{(29,30)}$.

Parity and maternal age were positively and negatively associated with the 'traditional' pattern that mainly comprised rice and beans. Rice and beans are some of the most frequently consumed food items in Brazil ${ }^{(31)}$ and are considered to be appropriate when consumed in moderation ${ }^{(32)}$. However, this pattern also comprised higher energy-dense foods such as potatoes and cassava, bread and sugar. As noted above, the scientific literature reveals that higher number of parturitions and younger age have been associated with a greater adherence to unhealthy patterns ${ }^{(11,16,27,28)}$. In our study, older women were more likely to adhere to the 'healthy' dietary pattern.

We did not observe associations between the sociodemographic factors and the 'mixed' pattern. This pattern was labelled 'mixed' because it comprised food groups with different nutritional compositions, such as eggs, bacon and mayonnaise, cakes and biscuits, and sardines. The majority of these food groups comprised more energy-dense foods. Some studies that have assessed sociodemographic factors and dietary patterns during pregnancy observed that factors such as smoking during pregnancy, living without a partner, higher parity, lower education and maternal age were positively associated with dietary patterns that are similar to the 'mixed' pattern in the present study ${ }^{(10,11,27,28)}$. Castro et al. ${ }^{(33)}$ showed that high adherence to the 'mixed' dietary pattern could decrease postpartum body weight loss. This may contribute to the maintenance of maternal overweight or an increase in the prevalence of obesity during the reproductive period.

No association was observed between skin colour and dietary pattern. This may be explained by the fact that more than $80 \%$ of the sample comprised black and brown women. Some studies on black-white dietary differences have shown that black populations tend to report lower intakes of vegetables, vitamin $\mathrm{C}, \mathrm{Ca}$ and $\mathrm{K}^{(34)}$. Lacerda et $a l .{ }^{(35)}$ found that compared with white women, black women tended to have higher energy and carbohydrate intakes during pregnancy and higher postpartum energy intake. Boggs et al. $^{\text {(36) }}$ identified two dietary patterns among the 41351 women enrolled in the Black Women's Healthy Study. At baseline, a lower score on the 'vegetables/fruit pattern' was associated with younger women and a higher score on the 'high meat/fried foods pattern' was associated with less educated women. Another possible explanation for the lack of association in our study may be that skin colour is a proxy for income.

Some limitations should be considered when interpreting our results. First, the cross-sectional design of the study does not allow for establishing causal relationships. Also, the FFQ previously validated for adults ${ }^{(20)}$ was not developed for pregnancy; however, epidemiological studies have shown that FFQ can be used to measure nutritional dietary intake during pregnancy with acceptable validity and reproducibility ${ }^{(7,10)}$, including in Brazil $^{(37)}$. Finally, the 
small sample size and the low-income profile of the sample must be considered when generalising the results.

Nevertheless, the study provides results that highlight the need to develop new understanding of dietary patterns during pregnancy. Moreover, the findings of the present study can be adopted in primary-care settings to provide new strategies for maternal dietary counselling during pregnancy and for women's health.

\section{Conclusion}

In summary, our study showed that sociodemographic factors may determine dietary patterns during pregnancy. Among other factors, income and parity, respectively, positively and negatively influenced food intake. Higher family income was associated with the 'healthy' pattern, whereas greater parity was associated with the 'traditional' pattern. These factors should be considered to provide pregnant women more appropriate and effective prenatal care.

\section{Acknowledgements}

Financial support: The project was supported by Fundação de Amparo à Pesquisa do Estado do Rio de Janeiro (Edital FAPERJ/SESDEC/MS/CNPq/no. 18/2009). The funder had no role in the design, analysis or writing of this paper. Conflict of interest: None. Authorship: M.B.T.d.C. designed the study, analysed and interpreted the data, and drafted the paper. A.A.F.V., A.S.D.O., M.C. and R.A.G.S. interpreted the data and drafted the paper. G.K. and R.S. designed the study and drafted the paper. All authors reviewed and approved the final version submitted for publication.

\section{References}

1. Wu G, Bazer FW, Cudd TA et al. (2004) Maternal nutrition and fetal development. J Nutr 134, 2169-2172.

2. Meinila J, Koivusalo SB, Valkama A et al. (2015) Nutrient intake of pregnant women at high risk of gestational diabetes. Food Nutr Res 59, 26676.

3. Lee SE, Talegawkar SA, Merialdi M et al. (2013) Dietary intakes of women during pregnancy in low- and middleincome countries. Public Health Nutr 16, 1340-1353.

4. Grieger JA \& Clifton VL (2014) A review of the impact of dietary intakes in human pregnancy on infant birthweight. Nutrients 7, 153-178.

5. Poston L, Harthoorn LF \& Beek EM (2011) Obesity in pregnancy: implications for the mother and lifelong health of the child. Pediatr Res 69, 175-180.

6. Purandare CN (2012) Maternal nutritional deficiencies and interventions. J Obstet Gynecol India 62, 621-623.

7. Poon AK, Yeung E, Boghossian N et al. (2013) Maternal dietary patterns during third trimester in association with birthweight characteristics and early infant growth. Scientifica 2013, 786409 .

8. Mamun AA, Callaway LK, O'Callaghan MJ et al. (2011) Associations of maternal pre-pregnancy obesity and excess pregnancy weight gains with adverse pregnancy outcomes and length of hospital stay. BMC Pregnancy Childbirth 11, 62.

9. Castro MBT, Souza RAG, Vilela AAF et al. (2014) Association between sociodemographics factors and dietary patterns during pregnancy. Rev Nutr 27, 173-181.

10. Arkkola T, Uusitalo U, Kronberg-Kippilä C et al. (2008) Seven distinct dietary patterns identified among pregnant Finnish women - associations with nutrient intake and sociodemographic factors. Public Health Nutr 11, 176-182.

11. Northstone K, Emmett P \& Rogers I (2008) Dietary patterns in pregnancy and associations with socio-demographic and lifestyle factors. Eur J Clin Nutr 62, 471-479.

12. Wirfält E, Drake I \& Wallström P (2013) What do review papers conclude about food and dietary patterns? Food Nutr Res 57, 20523.

13. Kant AK (2004) Dietary patterns and health outcomes. J Am Diet Assoc 104, 615-635.

14. Hu FB (2002) Dietary pattern analysis: a new direction in nutritional epidemiology. Curr Opin Lipidol 13, 3-9.

15. Sommer C, Sletner L, Jenum AK et al. (2013) Ethnic differences in maternal dietary patterns are largely explained by socioeconomic score and integration score: a populationbased study. Food Nutr Res 57, 21164.

16. Hoffmann JF, Camey S, Olinto MTA et al. (2013) Dietary patterns during pregnancy and the association with sociodemographic characteristics among women attending general practices in southern Brazil: the ECCAGe Study. Cad Saude Publica 29, 970-980.

17. Ricardo CZ \& Claro RM (2012) Custo da alimentação e densidade energética da dieta no Brasil, 2008-2009. Cad Saude Publica 28, 2349-2361.

18. Oken E, Kleinman KP, Olsen SF et al. (2004) Associations of seafood and elongated $n-3$ fatty acid intake with fetal growth and length of gestation: results from a US Pregnancy Cohort. Am J Epidemiol 160, 774-783.

19. Lohman TG, Roche AF \& Martorell R (1988) Anthropometric Standardization Reference Manual. Champaign, IL: Human Kinetics Books.

20. Sichieri R \& Everhart JE (1998) Validity of a Brazilian Food Frequency Questionnaire against dietary recalls and estimated energy intake. Nutr Res 18, 1649-1659.

21. Sichieri R (1998) Epidemiologia da Obesidade. Rio de Janeiro: EdUERJ.

22. Pinheiro ABV (1996) Tabela para Avaliação de Consumo Alimentar em Medidas Caseiras, $3^{\mathrm{a}}$ ed. Rio de Janeiro: Editora Atheneu.

23. Núcleo de Estudos e Pesquisas em Alimentação \& Universidade Estadual de Campinas (2006) Tabela Brasileira de Composiçã o de Alimentos, $2^{a}$ ed., p. 113. http://www. unicamp.br/nepa/taco/contar/taco_versao2.pdf (accessed July 2010).

24. US Department of Agriculture (2010) National Nutrient Database for Standard Reference, Release 23. http://www. nal.usda.gov/fnic/foodcomp (accessed July 2010).

25. Newby PK \& Tucker KL (2004) Empirically derived eating patterns using factor or cluster analysis: a review. Nutr Rev 62, 177-203.

26. Goñi L, Cuervo M, Santiago S et al. (2014) Parity implications for anthropometrical variables, lifestyle behaviors and dietary habits in pregnant women. An Sist Sanit Navar 37, 349-362.

27. Ferrer C, García-Esteban R, Mendez M et al. (2009) Determinantes sociales de los patrones dietéticos durante el embarazo. Gac Sanit 23, 38-43.

28. Cucó G, Fernández-Ballart J, Sala J et al. (2006) Dietary patterns and associated lifestyles in preconception, pregnancy and postpartum. Eur J Clin Nutr 60, 364-371.

29. Laaksonen M, Prattala R, Helasoja V et al. (2003) Income and health behaviours. Evidence from monitoring surveys 
among Finnish adults. J Epidemiol Community Health 57, 711-777.

30. Lenz A, Olinto MT, Dias-da-Costa JS et al. (2009) Socioeconomic, demographic and lifestyle factors associated with dietary patterns of women living in Southern Brazil. Cad Saude Publica 25, 1297-1306.

31. Souza A de M, Pereira RA, Yokoo EM et al. (2013) Most consumed foods in Brazil: National Dietary Survey 2008-2009. Rev Saude Publica 47, Suppl. 1, 190S-199S.

32. Brasil Ministério da Saúde (2014) Secretaria de Atenção à Saúde. Guia Alimentar para a População Brasileira. Brasília: MS; available at http://www.foodpolitics.com/wp-content/ uploads/Brazils-Dietary-Guidelines_2014.pdf

33. Castro MBT, Sichieri R, Brito FSB et al. (2014) Mixed dietary pattern is associated with a slower decline of body weight change during postpartum in a cohort of Brazilian women. Nutr Hosp 29, 519-525.

34. Kant AK, Graubard BI \& Kumanyika SK (2007) Trends in black-white differentials in dietary intakes of US adults, 1971-2002. Am J Prev Med 32, 264-272.

35. Lacerda EMA, Kac G, Cunha CB et al. (2007) Food intake during pregnancy and postpartum according to skin color in Rio de Janeiro, Brazil. Rev Saude Publica 41, 985-994.

36. Boggs DA, Palmer JR, Spiegelman D et al. (2011) Dietary patterns and 14-y weight gain in African American women. Am J Clin Nutr 94, 86-94.

37. Barbieri P, Nishimura RY, Crivellenti LC et al. (2013) Relative validation of a quantitative FFQ for use in a Brazilian pregnant women. Public Health Nutr 16, 1419-1426. 